the process of globalisation seen in particular over the past decade. In addressing this situation we have to accept the fact that governments and societies in the industrialised world do not have the social interest to address and resolve this problem (Sox, 2002), while governments and societies in many other regions of the world do not have as yet the financial strength to address and resolve this situation either. Thus, it is imperative that national associations and societies in psychiatry from both high-income nations and low- and middle-income countries prioritise this issue. These associations and societies need to work together to develop a strategic plan of action to address this mental health problem. The World Psychiatric Association (WPA) has never addressed this situation in a worldwide effort. The World Health Organization (WHO) has made reference to it but has not yet made it a priority. Therefore, we need psychiatry's leaders to bring this situation to the forefront of the profession. This issue is currently the greatest challenge to the mental health system worldwide. To continue to look the other way is both inhumane and unacceptable.

\section{References}

Garza-Trevino, E. S., Ruiz, P. \& Venegas-Samuel, K. (1997) A psychiatric curriculum directed to the care of the Hispanic patient. Academic Psychiatry, 21, 1-10.

Griffith, E. H. \& Ruiz, P. (1977) Cultural factors in the training of psychiatric residents in a Hispanic urban community. Psychiatric Quarterly, 49, 29-37.

Guynn, R. W. \& Ruiz, P. (1998) Aspectos didacticos relacionados con la psychiatria social. In Anales del XIV Congreso Nacional de Psiquiatria 'Honorio Delgado' (eds A. Perales, A. Saavedra, V. J. Acha, et al), pp. 137-143. Lima: Centro de Production Editorial de la UNMSM.

Matorin, A. A. \& Ruiz, P. (1999) Training family practice residents in psychiatry. International Journal of Psychiatry in Medicine, 29, 327-336.

Ruiz, P. (1987) A seven-year evaluation of a career-escalation training program for indigenous nonprofessionals. Hospital and Community Psychiatry, 27, 253-257.

Ruiz, P. (2003) WPA strives to disseminate relevant psychiatric knowledge via scientific meetings. World Psychiatry, 2, 63-64.

Ruiz, P. (2006) WPA scientific meetings: the link between sciences and quality of care. World Psychiatry, 5, 126-127.

Sox, H. C. (2002) Medical professionalism in the new millennium: a physician chapter. Annals of Internal Medicine, 136, 27-30.

\title{
Teaching and training in psychiatry
}

\section{David Skuse}

Behavioural and Brain Sciences Unit, Institute of Child Health, London WC1 1EH, UK, email d.skuse@ich.ucl.ac.uk

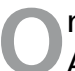
ne of the chief remits of the Board of International Affairs of the Royal College of Psychiatrists is to highlight, review, encourage and determine the development of psychiatric training, and to support trainees through collaboration in the development of curricula, as well as in relation to the conduct of examinations and continuing professional development. Here we present three more or less polemical articles that report on difficulties pertaining to the training of psychiatrists in Bangladesh, India and Europe. In each case, the authors turn to the College for advice, guidance and, potentially, intervention, with the aim of standardising the training of psychiatrists around the world.

Mohammad Mullick works in Bangabandhu Sheikh Mujib Medical University, in Dhaka, Bangladesh. Dhaka is situated on the banks of the Buriganga River and has a population of some 11 million. It is the largest city in Bangladesh and one of the fastest-growing cities in the world. In a country of over 120 million there are only 77 trained psychiatrists, and just two child psychiatrists for 47 million children under 15 years of age. While it would seem the quality of training is good, he asks how, given the limited resources available for aspirant psychiatrists, it is going to be possible to provide the numbers of mental health specialists required to deal with a vast and largely hidden need. He makes a number of suggestions about how the College could help, principally with a variety of schemes aimed at training the second generation of potential Bangladeshi psychiatrists. He does not discuss the substantial 'brain drain' of mental health workers from that country, a topic that has recently been reviewed by Adkoli (2006).

Professors Kulhara and Avasthi from Chandigarh, India, discuss the similar problems facing that country in its attempts to train a new generation of psychiatrists. One point they forcefully make concerns the extraordinary discrepancies between different regions of India in their provision of medical schools. The range is from just one small school in, for example, Chandigarh (with a population of 90 million) to 32 schools in Karnataka (population 56 million). Persuading medical students to consider a career in psychiatry is not easy at the best of times, and the relative lack of exposure to the specialty in curricula laid down by the Medical Council of India, together with lack of examinations in the subject, does not encourage many to select it. They review a range of problems, before turning to the College with a number of specific suggestions about how it might be able to help.

No doubt both the South Asian and European International Divisions of the College could have a role in responding to these pleas from the Indian subcontinent and to the third of our contributions, which concerns the state of psychiatric training in Europe. James Strachan draws our attention to an anomaly whereby the European Union requires mutual recognition of postgraduate specialist training schemes, but 
the content of those schemes is by no means subject to the scrutiny one might expect. He raises some interesting issues that deserve exploration in a future issue of International Psychiatry, for example the pressure being brought to bear by insurance companies upon medically trained psychotherapists, who deliver expensive treatment in comparison with non-medical professionals. This has parallels with the 'hospital medical officer' saga in the United States over the past decade and raises the spectre of what some have called the practice of 'bottom line' medicine.

\section{Reference}

Adkoli, B. V. (2006) Migration of health workers: perspectives from Bangladesh, India, Nepal, Pakistan and Sri Lanka. Regional Health Forum, 10, 49-58.

\title{
Teaching and training in psychiatry and the need for a new generation of psychiatrists in Bangladesh: role of the Royal College of Psychiatrists
}

\author{
Mohammad S. I. Mullick \\ Professor of Child and Adolescent Psychiatry, Department of Psychiatry, Bangabandhu Sheikh Mujib Medical University, Dhaka, \\ Bangladesh,email mullick@bdonline.com
}

angladesh is a small, populous South Asian nation with poor literacy, limited resources and a lack of basic healthcare. Caring for people with psychiatric disorders in such a setting is challenging. The prevalence of psychiatric disorder in Bangladesh is similar to that in other countries, yet there is a severe shortage of well trained psychiatrists and a lack of even basic mental health services. To generate large numbers of well trained psychiatrists, Bangladesh must expand its high-quality psychiatric training and education at both the postgraduate and the undergraduate levels. To achieve these ambitious goals, Bangladesh needs help and assistance from regional and international institutions. The Royal College of Psychiatrists can play a role of critical psychiatric public health importance by helping Bangladesh locally train a new generation of psychiatrists who will care for the vast number of those with ailments of mind and soul.

\section{Bangladesh: basic facts}

Bangladesh is densely populated, having a total area of $147570 \mathrm{~km}^{2}$ and a population of 123.85 million. About $45 \%$ of that population are under 18 years of age and $72 \%$ live in rural areas. Islam is the major religion (practised by around $88 \%$ of the population), followed by Hinduism (11\%). Most Bangladeshis share a common language and sociocultural heritage. The economy, which in large part depends on agriculture, is perennially affected by flood (Asiatic Society of Bangladesh, 2003). The average per capita income is US $\$ 444$ and the economic growth rate is around 6\% per annum (Bangladesh Bureau of Statistics, 2004).

\section{Extent of mental health problems in Bangladesh}

The prevalence of mental health problems in Bangladesh has been variously estimated to be between $7 \%$ and $16 \%$ (Chowdhury et al, 1981; Mullick \& Goodman, 2005). It is estimated that over 11 million adults and 8 million children and adolescents are in need of mental health services. Yet these people face both a lack of adequately trained mental health professionals and the absence of a structured mental health service.

\section{Evolution of teaching and training in psychiatry}

After Bangladesh achieved independence from Pakistan in 1971, undergraduate psychiatry training was established, with new departments of psychiatry. In 1979 a postgraduate course was started at the Bangladesh College of Physicians and Surgeons (BCPS). A course offering a Diploma in Psychological Medicine (DPM) began in 1975 at the former Institute of Postgraduate Medicine and Research (IPGM\&R, now the Bangabandhu Sheikh Mujib Medical University, BSMMU). This course was replaced by an MPhil course in 1995. In 2001, an MD course in psychiatry started at the BSMMU. 